\title{
VERTICAL INTEGRATION: APPLYING AN ECONOMIC CALCULUS TO KNOWLEDGE
}

\author{
Herman A. van den Berg \\ Faculty of Information Studies \\ University of Toronto \\ www.fis.utoronto.ca/phd/vandenberg
}

2005.01.19 
This paper applies an economic calculus to knowledge to address one of the most strategically important questions firms face - deciding which activities are more economically organized in a unified firm rather than in two autonomous firms. The conceptual and empirical framework presented here proposes that specialization leads to differences in cost and technical efficiency of knowledge-based factors of production between adjacent stages in a value chain. These divergent costs and technical efficiencies in turn shape the economics of inter-firm boundary location.

A number of dimensions are suggested as being useful for distinguishing among the tacit, codified, and encapsulated forms of productive knowledge inputs. Knowledge, so classified, is substituted for labour and capital as factors of production in the traditional microeconomic isocost-isoquant model. The research framework being proposed implies that differences in knowledge-based factor intensities are instrumental in the determination of economic inter-firm boundary location.

This paper is ground-breaking in its application of "an economic calculus to knowledge" (Simon, 1999: 34). It recognizes that "there are [factor] markets for knowledge..." and uses "...marginal rates of substitution between one form of knowledge and another" in applying microeconomic theory (Simon, 1999: 24).

Evidence for the propositions would imply that those making decisions regarding the location of inter-firm boundaries should give consideration to knowledge-based factor intensities in making their decisions to optimize firm performance.

Evidence found supporting the propositions would reinforce previous research suggesting the existence of a secular trend of increasing vertical de-integration of industries over time.

\section{Introduction}

"We are increasingly concerned... with knowledge as a factor of production, having costs and values that we must try to estimate in order to make correct decisions for the conduct of business... We have discovered that applying an economic calculus to knowledge... is often, because of... intangibility... far more difficult than costing and valuing... production machinery. Yet, whether we can make the measurements accurately or not, it is precisely these costs and values that determine the efficiency and profitability of our activities..." (Simon, 1999: 34)

The determination of economic inter-firm boundary location is a key strategic concern. Correctly deciding which activities are more economically organized "in a unified firm (AB) rather than in two autonomous firms (A and B)" (Williamson, 1999: 1097) is no simple undertaking. The question of firm boundary location is important since it attempts to predict the productive 
activities a firm should undertake in-house, which products it should purchase or activities it should outsource, and when it should sell its product to the next segment of the value system ${ }^{1}$ (Pfaffmann, 1998). This paper responds to that challenge in an innovative fashion by "applying an economic calculus to knowledge" (Simon, 1999: 34). The conceptual and empirical framework presented here proposes that specialization leads to differences in cost and technical efficiency of knowledge-based factors of production between adjacent stages along a value chain. These divergent costs and technical efficiencies in turn shape the economics of inter-firm boundary location.

Simon's (1999) urging to consider various forms of knowledge as factors of production in applying microeconomic theory may be considered somewhat novel. In assessing the contribution of R\&D to productivity growth, Griliches (1979: 95) introduced a production function that included "a measure of the current state of technological knowledge". Since then, the idea that "...there are markets for knowledge, with their supply and demand curves and marginal rates of substitution between one form of knowledge and another" (Simon, 1999: 24) appears to have received scant attention.

The framework constructed in this paper suggests that tacit, codified, and encapsulated forms of knowledge be considered as factors of production. This differentiation appears to be foundational and is operational even when adjacent stages of production rely on common substantive knowledge. Relative, rather than absolute, quantities of these factors of production will be gauged to reveal knowledge-based factor intensities, since agreement on what constitutes absolute quantitative measures of knowledge appears to be currently unobtainable (Down, 2000). Knowledge-based factor intensities may be considered a modernization of the microeconomic concept of labour or capital factor intensities $^{2}$ as traditionally applied in a manufacturing-based economy.

\section{Economics of Firm Knowledge}

The location of a boundary between upstream and downstream firms in a value system is a function of the marginal comparative advantages that emerge from knowledge specialization. These comparative advantages are manifested as differences in the slopes of firms' knowledge-based isoquant and isocost curves ${ }^{3}$. Comparative advantages surface as the relative abilities of firms engaging in knowledge-based activities increasingly specialize over time. The divergence of abilities that result from knowledge specialization will be manifested in the divergence of relative costs of tacit, codified and encapsulated knowledge within and among firms (Jacobides, 2003). 
For a given production function, the firm enjoying the minimum total cost of tacit, codified, and encapsulated knowledge will experience a comparative advantage. This firm is expected to integrate those knowledge-based factors of production. Upstream firms will sell to it and downstream firms will buy from it since they are at a comparative disadvantage in the production of the given good or service. The assumption of market transactions presupposes that gains from trade in excess of transaction costs exist.

Jacobides and Hitt (2003) have used a similar framework to empirically demonstrate that differences in productive capabilities along segments of a value system leads to dissimilar levels of vertical integration. Productive capabilities were defined as "...rest[ing] on the firm's general and specific knowledge..." (Jacobides and Hitt, 2003). Their findings of the mortgage banking industry in the US, in which fully integrated and specialized de-integrated firms co-existed, "suggest that specialization is a function of the relative productive capabilities in different parts of the value [system]" (Jacobides and Hitt, 2003).

\section{Classification of Organizational Knowledge}

The knowledge used by a firm to generate value may be characterized as being tacit, codified, or encapsulated. These three classifications of knowledge have been chosen based on differences in fundamental attributes that undergird all forms of substantive knowledge. Table I layers Boisot's (1998) three distinctions of knowledge over the tacit/explicit model suggested by Polyani (1966), Nonaka (1994), and Choo (1998), and the know-how/information model of Kogut and Zander (1992). Knowledge residing in individual brains (Boisot, 1998) is equated to tacit knowledge (Choo, 1998, Polanyi, 1966, Nonaka, 1994), while explicit knowledge (Choo, 1998, Polanyi, 1966, Nonaka, 1994) is classified as being either codified as information or encapsulated in a physical artefact (Boisot, 1998). Similarly, know-how (Kogut and Zander, 1992) is classified as either residing in individual brains or nested in physical artefacts (Boisot, 1998). The three classifications of knowledge displayed in Table I, tacit, codified, and encapsulated, will be used as knowledge-based factors of production. 


\begin{tabular}{|c|c|c|c|}
\hline Classification & Tacit Knowledge & Codified Knowledge & $\begin{array}{c}\text { Encapsulated } \\
\text { Knowledge }\end{array}$ \\
\hline Boisot's (1998) & $\begin{array}{c}\text { Knowledge residing in } \\
\text { individual brains }\end{array}$ & $\begin{array}{c}\text { Knowledge codified as } \\
\text { information }\end{array}$ & $\begin{array}{c}\text { Knowledge embodied } \\
\text { in physical artefacts }\end{array}$ \\
\hline $\begin{array}{c}\text { Polanyi (1966), } \\
\text { Nonaka (1994), } \\
\text { Choo (1998) }\end{array}$ & Tacit knowledge & Explicit knowledge & Explicit knowledge \\
\hline $\begin{array}{c}\text { Kogut and } \\
\text { Zander (1992) }\end{array}$ & Know-how & Information & Know-how (nested) \\
\hline
\end{tabular}

\section{Table I: Three Classifications of Knowledge}

It may be more useful to think of a given quantity of knowledge as having attributes or dimensions that place it closer to one classification than another, rather than rigidly categorizing it as belonging exclusively to one of these three classifications (Saviotti, 1998). Table II provides a select number of dimensions that may be useful as an aid in the determination of the most fitting classification for distinguishing a specific assembly of knowledge.

\begin{tabular}{|c|c|c|c|}
\hline Dimension & Tacit Knowledge & $\begin{array}{l}\text { Codified } \\
\text { Knowledge }\end{array}$ & $\begin{array}{l}\text { Encapsulated } \\
\text { Knowledge }\end{array}$ \\
\hline $\begin{array}{c}\text { Locus or } \\
\text { Knowledge } \\
\text { Substrate (Boisot, } \\
\text { 1998: 156) }\end{array}$ & Human mind & $\begin{array}{c}\text { Signs, symbols, } \\
\text { codes and display } \\
\text { rules }\end{array}$ & $\begin{array}{c}\text { Concealed in an } \\
\text { artefact's design and } \\
\text { technology; imbedded } \\
\text { in machines and other } \\
\text { physical technology } \\
\text { (Langlois, 2001) }\end{array}$ \\
\hline $\begin{array}{c}\text { Transfer and } \\
\text { Diffusion (Boisot, } \\
\text { 1998: 156) }\end{array}$ & $\begin{array}{l}\text { Hard to verbalize; requires } \\
\text { "rich modes of discourse" } \\
\text { (Choo, 2002: 265) and } \\
\text { "physical co-presence" } \\
\text { (Boisot, 1998: 46); costly to } \\
\text { diffuse broadly }\end{array}$ & $\begin{array}{l}\text { Easy and low cost } \\
\text { transfer \& storage; } \\
\text { subject to } \\
\text { involuntary transfer; } \\
\text { requires common } \\
\text { 'language' }\end{array}$ & $\begin{array}{l}\text { Speed, extent, and } \\
\text { cost of transport all } \\
\text { dependent on } \\
\text { physical } \\
\text { characteristics }\end{array}$ \\
\hline
\end{tabular}




\begin{tabular}{|c|c|c|c|}
\hline Dimension & Tacit Knowledge & $\begin{array}{l}\text { Codified } \\
\text { Knowledge }\end{array}$ & $\begin{array}{l}\text { Encapsulated } \\
\text { Knowledge }\end{array}$ \\
\hline Expression & $\begin{array}{l}\text { Implicit in action-based } \\
\text { skills (Polanyi, 1966) and } \\
\text { conversation (Simon, 1999) }\end{array}$ & $\begin{array}{c}\text { Rules, routines and } \\
\text { recipes based on a } \\
\text { system of symbols } \\
\text { (Nelson and Winter, } \\
\text { 1982) }\end{array}$ & $\begin{array}{l}\text { Embodied in artefacts } \\
\text { (Boisot, 1998) }\end{array}$ \\
\hline $\begin{array}{l}\text { Acquisition } \\
\text { Process }\end{array}$ & $\begin{array}{l}\text { Experiencing and doing, } \\
\text { observation and imitation, } \\
\text { internship and } \\
\text { apprenticeship. } \\
\text { “...teachable even though } \\
\text { not articulable" (Winter, } \\
\text { 1987: 171) }\end{array}$ & $\begin{array}{c}\text { Interpretation of } \\
\text { signs, symbols, } \\
\text { codes, and displays; } \\
\text { dependent on IPR } \\
\text { regimes }\end{array}$ & $\begin{array}{l}\text { Acquired in markets } \\
\text { through trade }\end{array}$ \\
\hline $\begin{array}{c}\text { Source of } \\
\text { Economic Value }\end{array}$ & $\begin{array}{l}\text { Capacity to make intuitive } \\
\text { judgements, discoveries } \\
\text { and innovations }\end{array}$ & $\begin{array}{l}\text { Informing the } \\
\text { interpreter; Low cost } \\
\text { replication; non- } \\
\text { rivalrous nature } \\
\text { (Romer, 1990) }\end{array}$ & $\begin{array}{l}\text { Use of the artefact } \\
\text { incorporating the } \\
\text { encapsulated } \\
\text { knowledge }\end{array}$ \\
\hline Observability & Requires co-location & $\begin{array}{c}\text { Limited } \\
\text { excludability } \\
\text { (Langlois and } \\
\text { Robertson, 1996, } \\
\text { Saviotti, 1998) }\end{array}$ & $\begin{array}{l}\text { Requires costly } \\
\text { experimentation and } \\
\text { reverse engineering }\end{array}$ \\
\hline
\end{tabular}

Table II: Dimensions useful for Knowledge Classification

\section{Knowledge Boundaries as Firm Boundaries}

"Firms... form a pattern of economic organization that takes into account the need for acquiring knowledge in a more specialized fashion..." The "vertical boundaries of a firm are determined by... the economics of conservation of expenditures on knowledge" (Demsetz, 1988: 160).

\section{Productivity and Specialization}

Firm productivity is enhanced through specialization, and firms, like individuals, can improve their economic prospects through specialization in knowledge acquisition (Demsetz, 1988, 1991). The introduction of the notion that specialization is productive has been attributed to Adam Smith in his discussion of the division of labour among individual workers within a firm. Demsetz 
$(1988,1991)$ extends this idea to consider productive specialization among firms. Firms are "repositories of specialized knowledge and of the specialized inputs required to put this knowledge to work" (Demsetz, 1988: 158). Hence, "Economic organization, including the firm, must reflect the fact that knowledge is costly to produce, maintain, and use [and that] ...there are economies to be achieved through specialization" (Demsetz, 1988: 158). Just as division of labour and leads to productivity increase, so too does division of knowledge lead to human capital deepening and economic efficiency.

Grant (2002) concurs with Demsetz, on the economic imperative of specialization and also makes the link to knowledge. The firm exists because it provides "conditions under which individuals can integrate their specialist knowledge" and because knowledge for production "requires greater specialization than is needed for its utilization" (Grant, 2002). This difference between knowledge required to produce and knowledge required to use a product is termed the "fundamental asymmetry in the economics of knowledge" (Grant, 2002). Grant goes so far as to claim that "[t]he assumptions that there are gains from specialization in knowledge acquisition and storage, and that production requires the input of a wide range of specialized knowledge... is fundamental to all theories of the firm" (2002: 112) (emphasis added).

\section{Common Substantive Knowledge}

The observation that productive activities reliant on vastly different substantive knowledge occur in separate firms should surprise no one. But, when productive activities relying on common substantive knowledge are adjacent to each other in an industry's value system, it is a more subtle specialization that determines whether or not these activities are separated by inter-firm boundaries. The research initiative being presented here suggests that this subtlety is may be ascribed to specialization leading to differences in the unique combinations of tacit, codified and encapsulated knowledge used as factors of production in adjacent stages. Such differences may be captured by measuring variation in knowledge-based factor intensities of adjacent production and cost functions.

The occurrence of a series of adjacent stages of production is commonplace in the complex productive value systems of many industries. The decision to use adjacent stages in the research being proposed here ensures the presence of considerably more common knowledge than if the stages were not adjacent. This has the effect of minimizing the probability that the presence of an inter-firm boundary is merely due to an inability to integrate vastly different knowledge domains. Instead, it raises the likelihood that de-integration is driven by subtle 
differences in the relative tacitness of related substantive knowledge. The decision to focus on differences in knowledge-based factor intensities between adjacent stages of production along a value system also enhances the possibility that the research outcomes may be generalizable to other multi-stage industries.

\section{Research Questions}

What determines the location of a firm's vertical boundaries? How can differences in the economics of knowledge acquisition explain inter-firm boundary locations? How can the nature of knowledge explain these differences?

The theoretical background chosen to examine these overarching questions is the knowledge-based view of the firm (KBV). In particular, Demsetz's (1988) proposition that divergent knowledge acquisition costs are instrumental, Griliches' (1979) and Simon's (1999) promotion of knowledge as a factor of production, and Boisot's (1998) three classifications of knowledge have been highlighted. Specialization, expressed as differences in knowledge-based factor intensity, is posited to be instrumental in the formation of inter-firm boundaries along a value system with common substantive knowledge.

It is anticipated that differences in the nature of knowledge, as expressed in Table II, can be demonstrated to be fundamental in shaping the differences in relative productivity of tacit, codified and encapsulated knowledge among adjacent stages of production. While productive activity may generally be considered transformation of tacit knowledge into some form of explicit knowledge (Hedlund, 1994), few (if any) stages of production along a value chain are able to rely on exclusively on tacit, codified or encapsulated knowledge. After all, "...there is a limit to the extent to which one factor of production can be substituted for another..."(Robinson, 1933: 330).

Each stage along a value chain is expected to make use of that combination of factors which is uniquely most efficient (output maximizing while cost minimizing). It is therefore expected that different combinations of tacit, codified and encapsulated knowledge inputs will be evident between adjacent stages of production.

To research Demsetz's (1988) assertion, tacit and explicit knowledge are substituted for labour and capital as factors of production in the traditional microeconomic isocost-isoquant model ${ }^{4}$ as shown in Figure 1. As constructed, Figure 1 suggests that adjacent stages of production may be distinguished by comparative advantages in tacit or explicit knowledge input factors. ${ }^{5}$ The upstream stage, on the left side of the figure, has a comparative advantage in 
production requiring a relatively higher quantity of tacit knowledge, while the downstream stage, on the right side of the figure, has a comparative advantage in production requiring a relatively higher quantity of explicit knowledge. Upstream production may be described as being more tacit knowledge intensive relative to the downstream production.

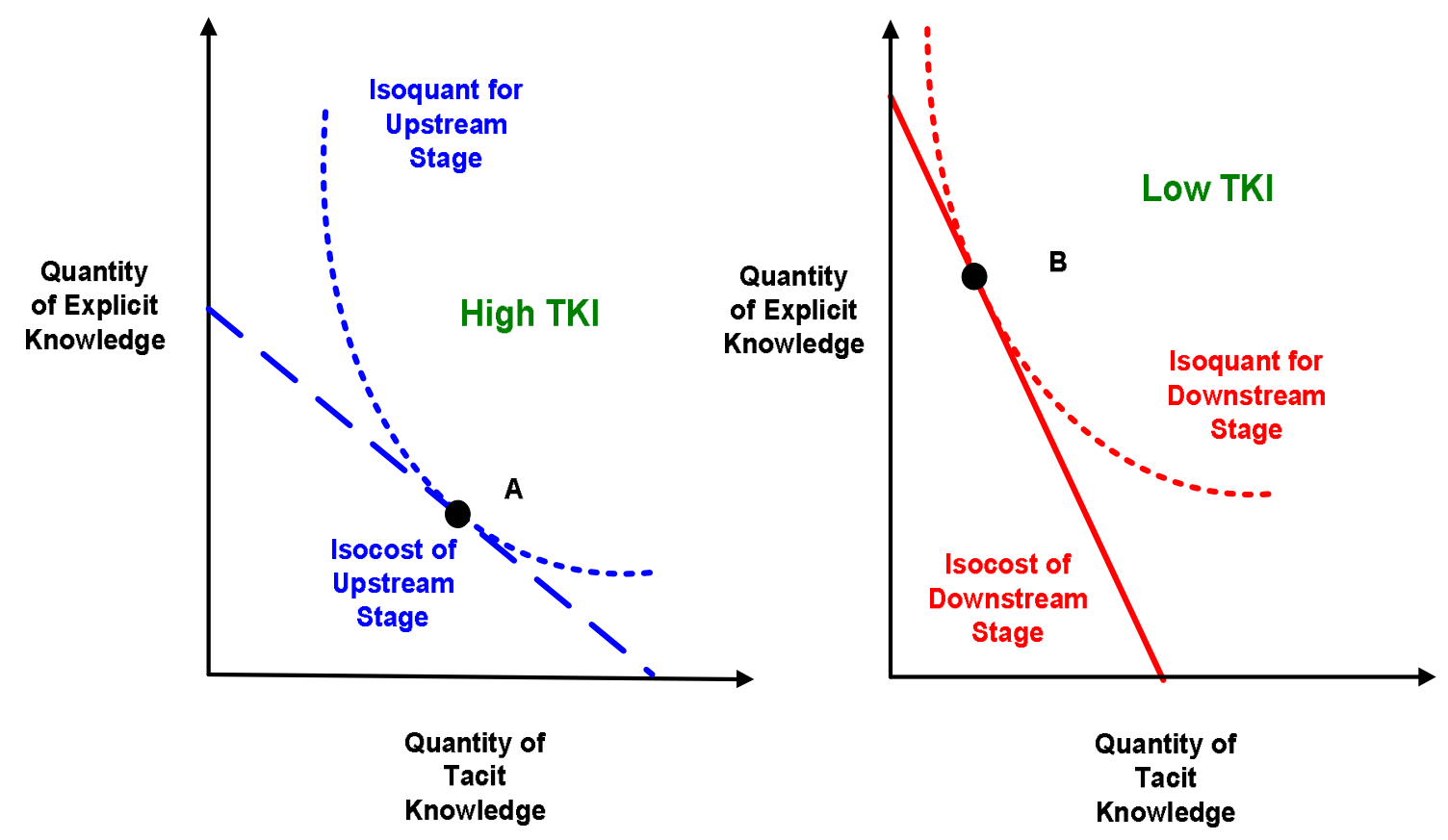

Figure 1: Knowledge-Based Comparative Advantage

Factor intensity is used to compare relative factor usage between stages. If the quantity of tacit knowledge is given on the horizontal axis and the quantity of explicit (codified and encapsulated) knowledge is given on the vertical axis, then we can consider production in the upstream stage as tacit knowledge intensive relative to production in the downstream stage. Consistent with microeconomic tradition, the negative inverse of the slope of the isocost and isoquant curves are termed, tacit knowledge intensity or TKI. ${ }^{6}$

When cost is minimized for a given quantity of output, or when output is maximized for a given total cost, the slopes of the isocost curve and that the isoquant curve will be identical as at points " $A$ " and "B" in Figure 1. At other points along the isoquant curves, the slopes vary due to the law of diminishing marginal product. ${ }^{7}$ Therefore, to distinguish between the TKI of the cost of production (the negative inverse of the slope of the isocost line) and the TKI of the quantity of production (the negative inverse of the slope of the isoquant curve), they will be subscripted with " $\mathrm{C}$ " and " $\mathrm{Q}$ ", respectively. 
The choice of relying on factor intensity as a relative quantitative measure in this research is deliberate. While economists may generally agree on how quantities and costs of labour and capital may be measured, consensus on the measurement of absolute quantities and costs of tacit and explicit (codified and encapsulated) knowledge has yet to be achieved (Down, 2000). By seeking to measure the relative reliance of a production or cost function on tacit versus codified versus encapsulated knowledge along the dimensions laid out in Table II, the intractability of obtaining absolute quantitative measures of these factors is circumvented.

The following section formalizes the questions relating the location of vertical inter-firm boundaries to differences in the relative costs and productivity of tacit and explicit (codified or encapsulated) knowledge.

\section{Specialization}

In his seminal The Theory of the Firm Revisited, Demsetz (1988) suggests that firms exist to create economic value by lowering the cost of production of a good or service below the cost that is achievable through the self-provision of the same product by individuals or households. Advantages in production costs stem from specialization of tasks which in turn stem from specialization of knowledge (Demsetz, 1988).

The firm seen as an agreement to specialize (Demsetz, 1988, Grant, 2002), suggests different marginal rates of technical substitution among the various factors of production between adjacent production stages. In other words, adjacent stages of production will operate on different isoquant curves, as modeled in Figure 1 due to differences between the unique production functions in upstream and downstream stages.

Demsetz (1988) describes the boundaries of firms being located as a function of (i) low cost knowledge encapsulation (in production) on the part of the supplier, and (ii) low information costs (in product utilization) on the part of the consumer of such encapsulated knowledge. Production of an intermediate product by an upstream firm at the minimum isocost for a given output of intermediate product corresponds to Demsetz's (1988) reference to low cost encapsulation on the part of the supplier. Similarly, production of the intermediate product by the upstream firm at the maximum isoquant is consistent with minimizing input costs for the downstream firm.

Specialization in knowledge may emerge as differences in both $\mathrm{TKI}_{\mathrm{C}}$ and $\mathrm{TKI}_{\mathrm{Q}}$ between adjacent stages of production, reflecting differences in the relative cost of the factors and differences in the production function between stages. This may be the case even when they share a common substantive knowledge. 
Differences are expected to emerge in knowledge-based capabilities critical to sustaining a comparative advantage because their development is path dependent, firm-specific, and socially embedded, having evolved over some period of time (Dierickx and Cool, 1989, Barney, 1991). It would therefore be reasonable to expect to measure differences in both $\mathrm{TKI}_{C}$ and $\mathrm{TKI}_{\mathrm{Q}}$ along a value chain or system.

The different slopes of the two isocost lines in Figure 2 indicated differences in $\mathrm{TKI}_{\mathrm{C}}$ between the upstream and downstream stages. In Figure 2, the upstream production stage has relatively higher TKIc per unit of cost than the downstream firm. While differences in factor intensity along a value system have been observed when the traditional microeconomic factors of labour and capital have been measured, differences in knowledge-based factor intensity have yet to be observed. Therefore to empirically test the basic construction on which later hypotheses rest, the following is first proposed.

Proposition 1: The TKIC for a given cost of production differs between adjacent vertical stages in a value chain.

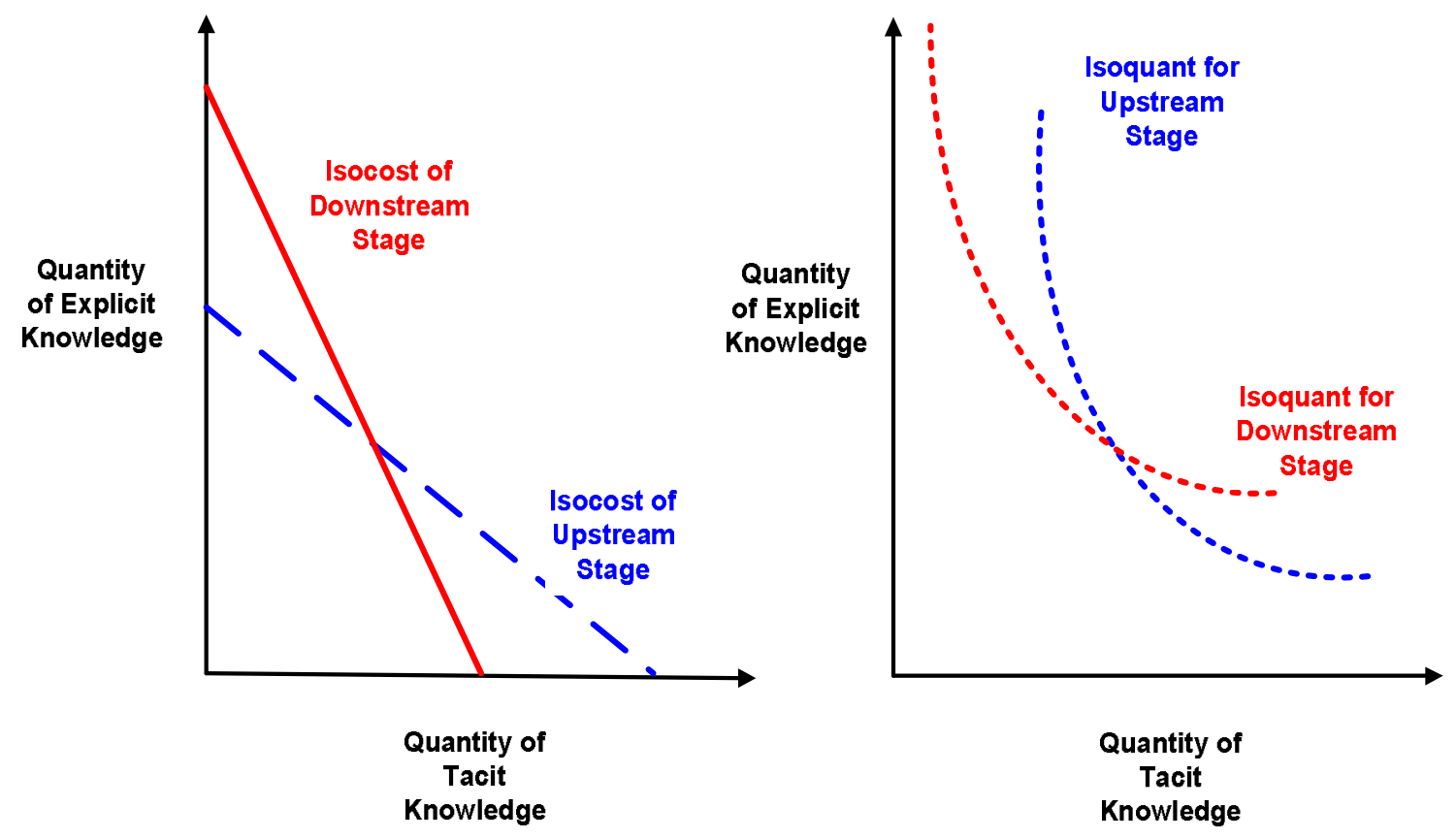

Figure 2: Evidence of Specialization

The different locations of the two isoquant curves in Figure 2 are also indicative of differences in $T K I_{Q}$ between the upstream and downstream stages. In Figure 2 , the upstream production stage has relatively higher TKI $I_{Q}$ per unit of product than the downstream firm suggesting that the two stages rely on different 
production functions. The upstream (downstream) product isoquant is drawn relatively closer to the horizontal (vertical) axis, demonstrating the requirement for relatively more explicit (tacit) knowledge for technically efficient production. To empirically test this construction more generally, the following is also proposed:

Proposition 2: The $T K I_{Q}$ for a given quantity of production differs between adjacent vertical stages in a value chain.

While it would be surprising if evidence did not support these first two propositions, they are included for completeness and to form the basis for subsequent propositions.

\section{Production Efficiency}

The work of Demsetz (1988), Pfaffmann (2000, 1998) \& Jacobides \& Hitt (2003), suggests that the position of firms, both upstream and downstream of an interfirm boundary or market interface, will be selected so as to maximize their productive efficiencies along a value system. While upstream and downstream firms sharing an inter-firm boundary will be engaged in complementary tasks due to their adjacency in the value system (Pfaffmann, 2000), they will be engaged in dissimilar tasks based on their specialized knowledge. Due to their respective knowledge specialization, each firm will be able to enjoy a comparative advantage 8 in the productive activities associated with its specialty.

Argyres (1996) proposed that firms vertically integrate into those activities in which they had relatively superior capabilities and outsource those in which they have inferior capabilities. He found support for his proposition in that lack of shared or intersecting knowledge between two adjacent activities in a value chain led to a boundary between them (Argyres, 1996). One relatively tacitknowledge-based activity, mould-making, occurred in an upstream firm while the second relatively more formalized-knowledge-based activity, design engineering, was located in the downstream firm under study (Argyres, 1996). This example of vertical de-integration occurred despite "the molds' complete customization and high cost imply[ing] high physical asset specificity" which would argue for vertical integration according to traditional transaction cost economic theory (Argyres, 1996: 137).

It is expected from Argyres (1996), that products most efficiently produced with relatively higher levels of $\mathrm{TKI}_{\mathrm{Q}}$ (isoquant curves relatively closer to the horizontal axis than the vertical axis in Figure 1) will be produced by firms with relatively higher $\mathrm{TKI}_{C}$ in input costs (flatter isocost lines), ceteris paribus. This is depicted at point " $\mathrm{A}$ " of in the left-hand or upstream graph in Figure 1. Correspondingly, products most efficiently produced with relatively lower $\mathrm{TKI}_{\mathrm{Q}}$ 
(isoquant curves relatively closer to the vertical axis than the horizontal axis in Figure 1) will be produced by firms with relatively lower $\mathrm{TKI}_{C}$ in input costs (steeper isocost lines), ceteris paribus. This is depicted at point " $\mathrm{B}$ " of the righthand or downstream graph in Figure 1.

For the downstream producer to produce the upstream product it would have to incur higher total input costs, as would the upstream firm to produce downstream product. Graphically, this would be represented by an isocost line for the downstream (upstream) firm, parallel to its current position and tangent to the upstream (downstream) product isoquant curve. The new isocost curve would be above, or to the right of, the existing isocost line, indicating a combination of input factors with higher total costs. The most economically efficient combination occurs when the upstream firm's isocost line is just tangent to the upstream product's isoquant at point " $\mathrm{A}$ ", while the downstream firm's isocost line is tangent to the downstream product's isoquant at point " $\mathrm{B}$ ". In other words, the $\mathrm{TKI}_{\mathrm{Q}}$ for a given quantity of production for a given vertical stage in a value chain is expected to be positively correlated with the $\mathrm{TKI}_{C}$ for the corresponding cost of production. This aspect of the model can be hypothesized as:

Proposition 3: The higher the $T K I_{Q}$ for a given quantity of production in a vertical stage in a value chain, the higher will be the TKI for the corresponding cost of production in that stage.

For this hypothesis to hold, the vertical stages of production must be subject to the discipline of a competitive environment ensuring production efficiency in which quantities of production are maximized and cost of production are minimized. The more efficient the production process, the less likely quantity will be below the optimal maximum (on an isoquant closer to the origin) and costs above the optimal minimum (on an isocost more distal from the origin). While not being tested directly, the extent to which Proposition 3 does not hold may be a function of systemic production inefficiencies rather than a lack of positive correlation between $\mathrm{TKI}_{\mathrm{Q}}$ and $\mathrm{TKI}_{\mathrm{C}}$. To avoid lack of competition being a confounding variable requires the selection of an industry in which competition is extensive.

\section{Vertical Integration or De-Integration}

Grant and Baden-Fuller (2004: 69) hypothesize that "Increasing marginal costs of knowledge integration within the firm imply that, where products require a broad range of different knowledge types, efficiency of integration is maximized through separate firms specializing different areas of knowledge..." While evidence in support of the first two propositions may indicate that dissimilarity 
in TKI can give explanation to differences observed along a value chain, it does not identify the location of inter-firm boundaries. The magnitude of differences in $\mathrm{TKI}_{\mathrm{Q}}$ and $\mathrm{TKI}_{\mathrm{C}}$ found in adjacent vertical stages of a value chain are, however, expected to be reflective of the extent of specialization. The size of differences in TKI are therefore posited to be determinant of whether or not adjacent stages of production are found to be integrated in one firm or separated in two.

The benefits of specialization are reaped by firms who concentrate their efforts in those stages of production in which they have a comparative advantage while exiting those stages in which they are at a disadvantage. One reason for separating adjacent stages that differ in TKI into separate firms is to avoid managerial diseconomies of scope (Lawrence and Lorsch, 1967, Jacobides and Hitt, 2003). Firm-wide application of common management practices, or dominant logics (Prahalad and Bettis, 1986), may hinder productivity in some stages of the value chain, where more focused management could enhance it (Jacobides and Hitt, 2003). Inefficiencies due to diseconomies of scope move production isocost lines closer to the origin and tangent to lower isoquant curves.

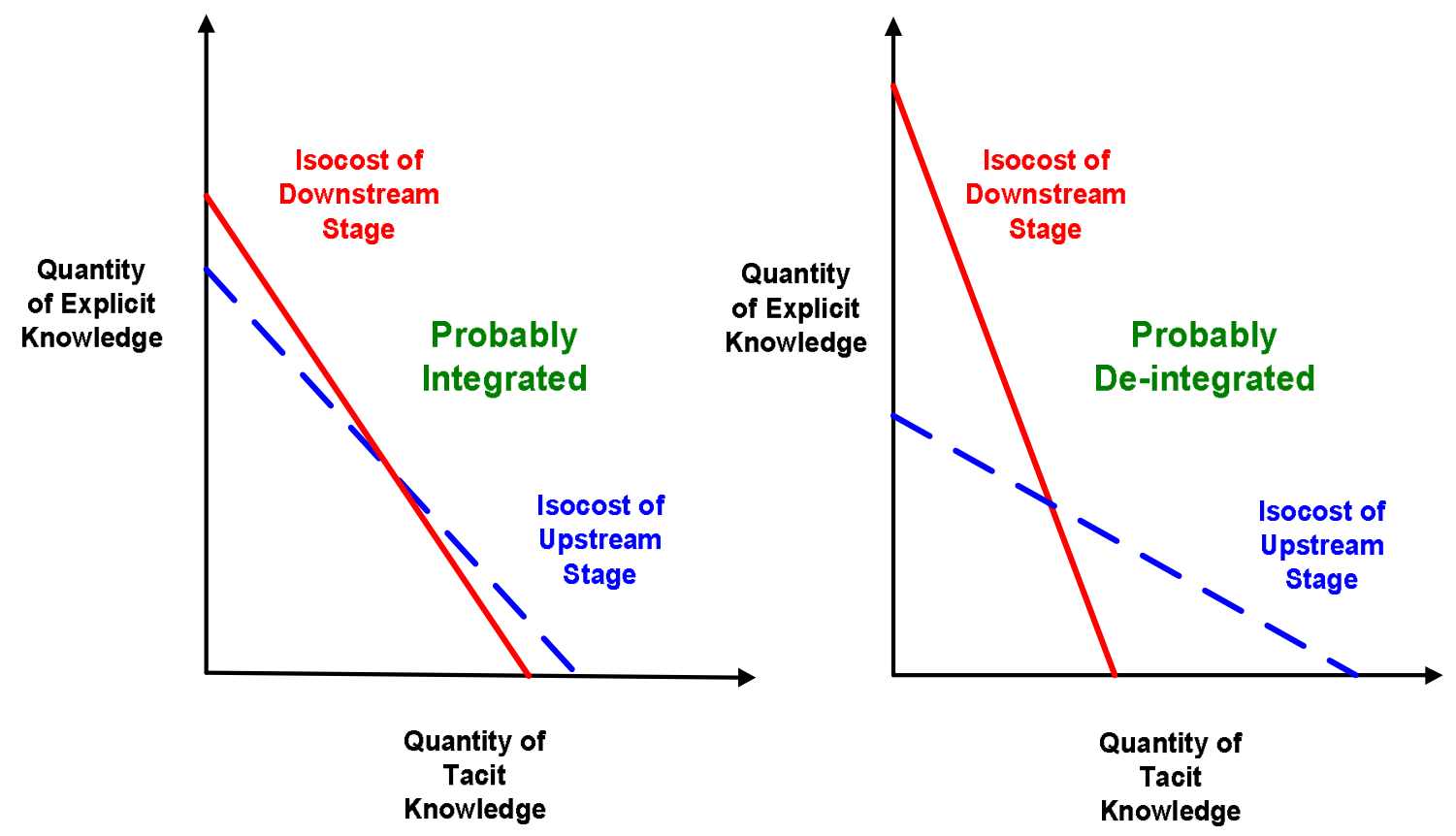

Figure 3: Probability of Integration based on Cost Function

The left-hand graph in Figure 3 depicts the isocost curves of the upstream and downstream stages as being close to identical, indicating that TKIC for the two stages is similarly close to indistinguishable. In such a case there would be relatively little difference in efficiency faced by either stage in producing tangent 
to any given isoquant curve. Faced with similar TKIs in cost of production, upstream and downstream stages could be economically integrated in a single firm.

In the right-graph in Figure 3 however, the isocost curves are not similarly positioned. The TKIC of the upstream producer is higher, indicating that this stage of production faces a relatively low cost of tacit knowledge. Conversely, in the right-hand graph in Figure 3, the $\mathrm{TKI}_{\mathrm{C}}$ of the downstream producer is lower, indicating that this stage of production faces a relatively high cost of tacit knowledge. One can easily imagine that only in rare circumstances would both isocost curves be equally efficient, with both being tangent to a given isoquant curve. Faced with such differences in TKI , there is less of a possibility that both stages of production will be found in a single firm. Based on this construction, the following is proposed.

Proposition 4: The greater the difference in the TKIC for a given cost of production between adjacent stages in a value chain, the greater the probability that these stages will be separated by an inter-firm boundary.

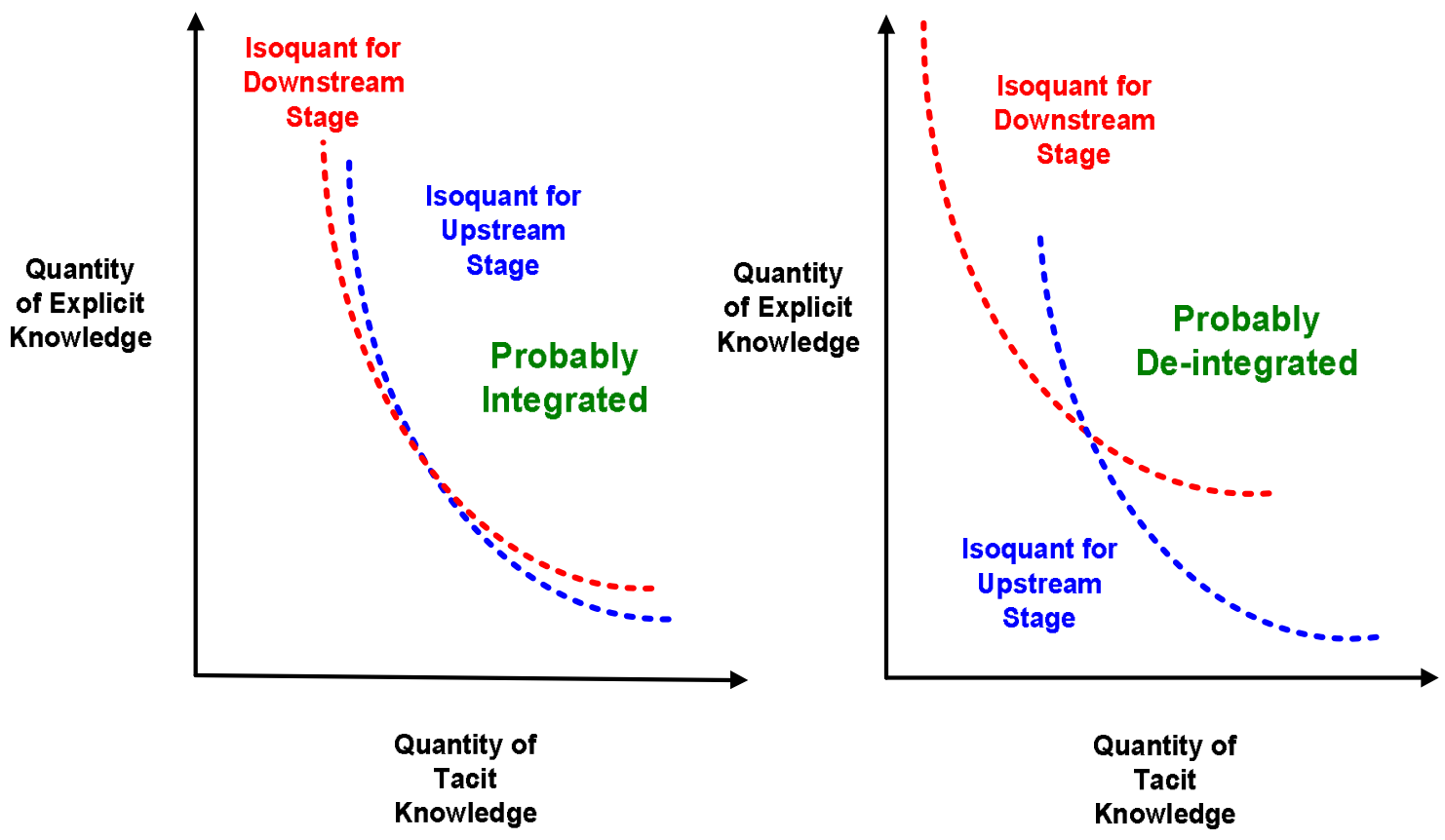

Figure 4: Probability of Integration based on Production Function

Similarity of $\mathrm{TKI}_{\mathrm{Q}}$ for a given quantity of production, as reflected by the colocation of the isoquant curves of both upstream and downstream products, argues for the vertical integration of the two stages of production in a single firm. If the upstream and downstream isoquants of adjacent stages of production are 
nearly co-located, as depicted in the left-hand graph of Figure 4, it would indicate little dissimilarity in the $\mathrm{TKI}_{\mathrm{Q}}$. The less unique the combination of knowledge inputs of the adjacent stages' production function, the greater the probable intersection of substantive knowledge associated with productive tasks. In the extreme, if the isoquants of adjacent upstream and downstream stages are nearly identical, it could indicate essentially no difference in underlying substantive knowledge. In that case, one could expect of the two vertical stages of production to be combined in a single firm.

The different locations of the upstream and downstream isoquants in the righthand graph of Figure 4 are indicative of two knowledge mature products. Knowledge maturity indicates that the substantive knowledge used in the production of the two products differs. As a result, it is more economical for the downstream producer to purchase the specialized competences of the upstream firm as codified or encapsulated knowledge without having to acquire the underlying substantive knowledge (Pfaffmann, 1998, Pfaffmann, 2000). Similarly, it is more economical for the upstream firm to sell an intermediate product rather than develop it further through the downstream stage.

The importance of the relative locations of upstream and downstream product isoquants in the determination of vertical integration may be formalized as follows.

Proposition 5: The greater the difference in the $T K I_{Q}$ for a given quantity of production between adjacent stages of a value chain, the greater the probability that the stages will be separated by an inter-firm boundary.

Operation at the tangency of an isocost and isoquant by a firm presupposes that the firm is operating at close to perfect efficiency (i.e., correlation in Proposition 3 $=+1$ ). In reality, it is expected that firms will incur costs in excess of the theoretically efficient isocost, and produce at some volume slightly less than the theoretically efficient isoquant (i.e., correlation in Proposition $>0$, and approaching 1).

\section{Dynamic Unbundling}

Jacobides (2003) argues that there has been little work to date, on explaining how markets linking two stages of the value chain arise. According to Jacobides (2003: 1), “...neither institutional economists nor their critics study how or why intermediate markets emerge. At the empirical level, there is scant research on the emergence of a 'vertical discontinuity,' an intermediate market."

As knowledge specialization progresses over time within firms, heterogeneity of productive capabilities appear through selection and replication processes 
(Jacobides and Winter, 2003). Gains from specialization as embodied in heterogeneous capabilities motivate organizational unbundling and the emergence of new markets (Jacobides and Winter, 2003, Jacobides, 2003). Unbundling requires "simplification of coordination between different parts of the value chain, and the standardization of information that needs to be exchanged between them" (Jacobides, 2003: 2-3). Balconi (2002) suggests that codification and encapsulation in computer-based technology leads to vertical de-integration, while Macher and Mowery (forthcoming, 2004) associate industry maturation in computers and chemicals industries with technical standardization and codification of formerly tacit knowledge. Standardization changes factor intensities: tacit knowledge intensity falls as production processes are made explicit over time.

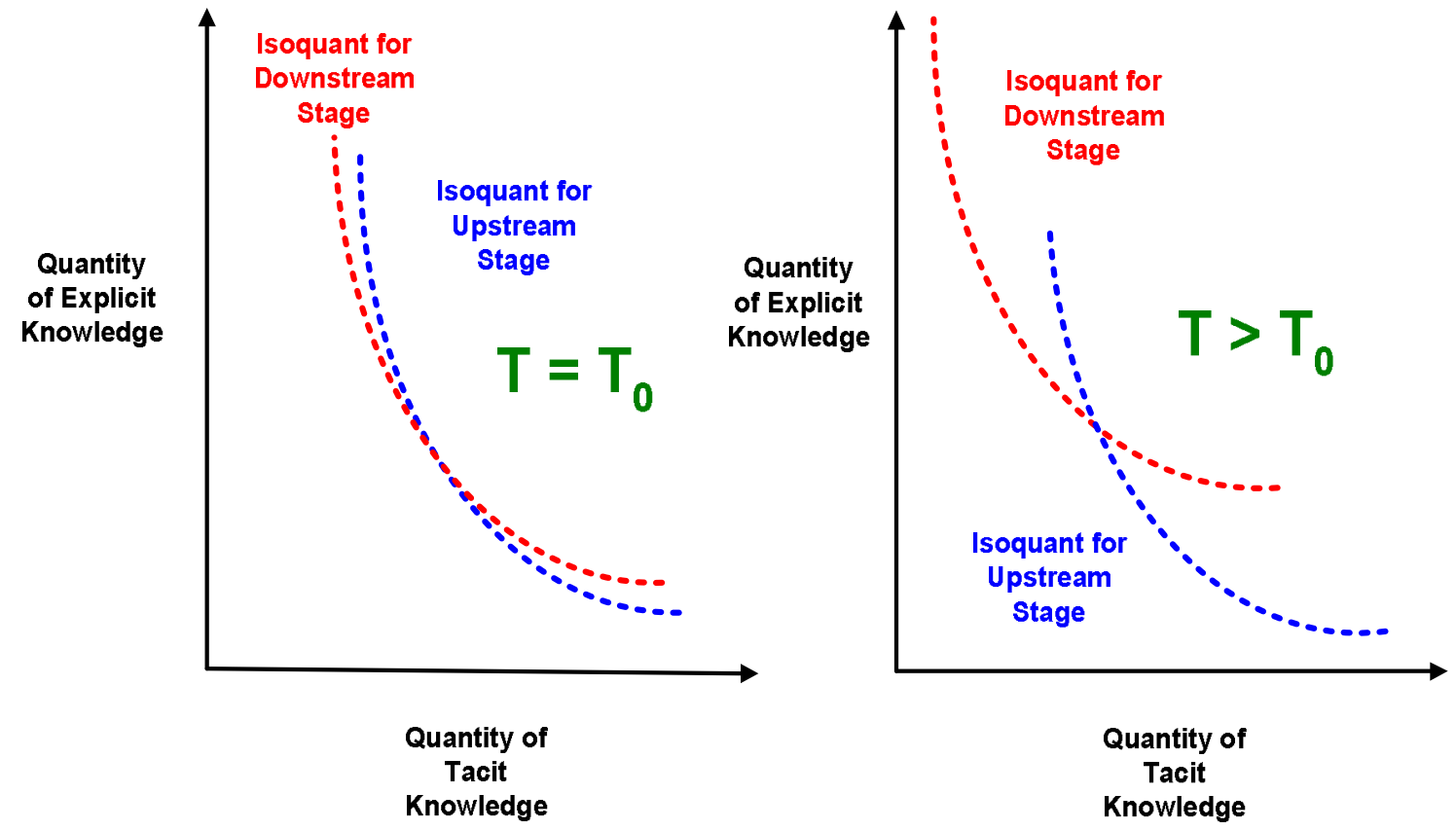

Figure 5: Dynamic Unbundling of Production Function

Jacobides (2003), and Jacobides and Winter (2003) suggests that isoquant curves in adjacent stages of a value chain drift apart over time as a result of knowledge specialization, while Macher and Mowery (forthcoming, 2004) suggest that this drift will be up and to the left for at least one stage's isoquant. Using the two graphs in Figure 5, for example, this could be represented by showing the upstream and downstream isoquant curves being initially co-located and then drifting apart to their new locations. The phenomenon of dynamic unbundling may be formally hypothesized as follows. 
Proposition 6: Over time, differences in the $T K I_{Q}$ for a given quantity of production will increase between adjacent stages of a value chain.
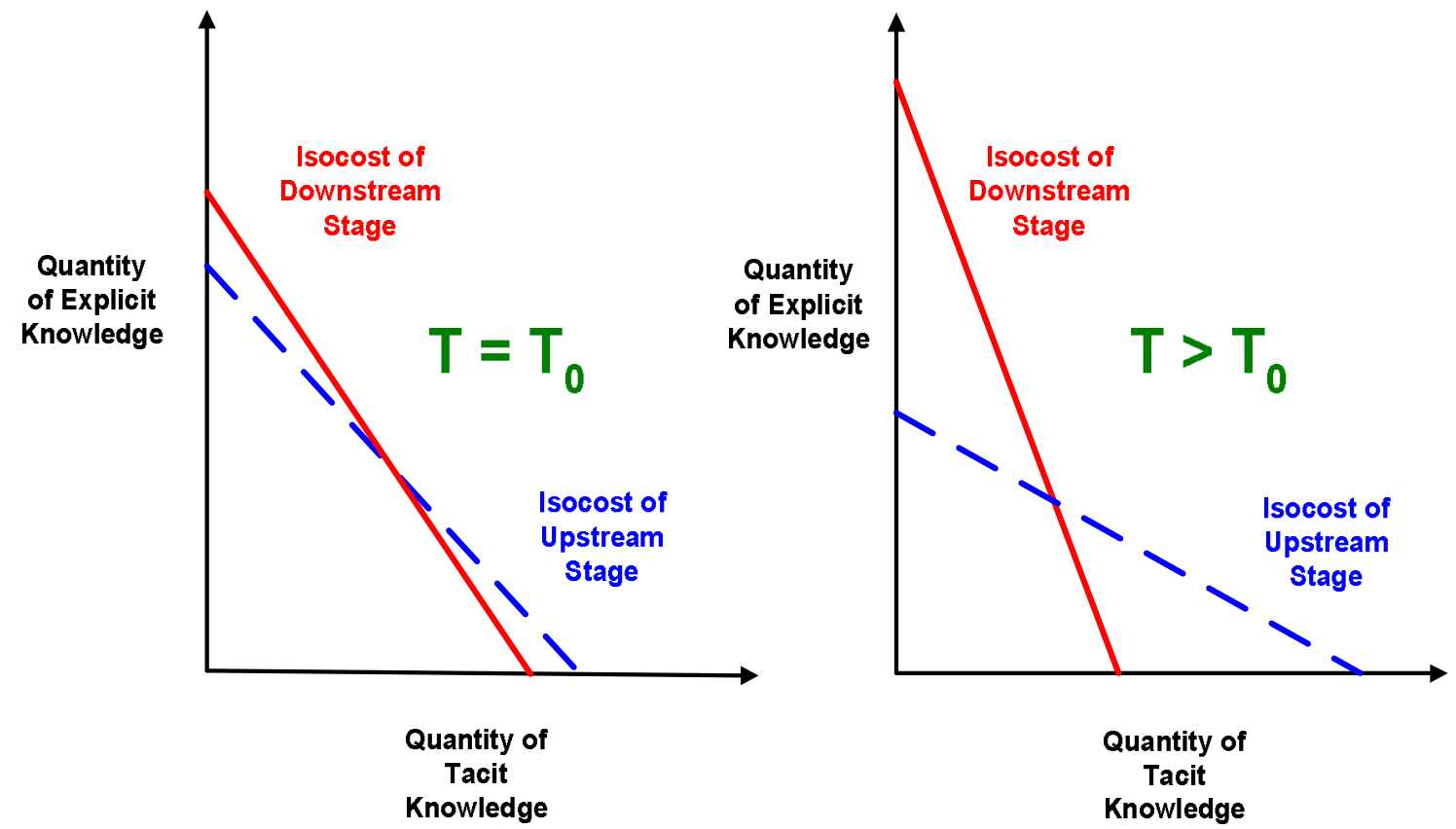

Figure 6: Dynamic Unbundling of Cost Function

If $\mathrm{TKI}_{\mathrm{C}}$ for costs and $\mathrm{TKI} \mathrm{Q}_{\mathrm{Q}}$ for quantities of production continue to be positively correlated through the dynamic unbundling as hypothesized in Proposition 3, then the isocost lines and isoquant curves will remain tangent as at points " $\mathrm{A}$ " and " $\mathrm{B}$ " on the graphs in Figure 1. This would imply that as isoquant curves drift, the most cost efficient combination of factor inputs would also change as depicted in Figure 6. This tendency to drift may be formally hypothesized as:

Proposition 7: Over time, differences in the TKI for a given cost of production will increase between adjacent stages of a value chain.

\section{Performance Effects}

In most industries there will be some heterogeneity of performance in any given stage of production. An examination of factor intensities may shed some light on the cause of such heterogeneity. Proposition 3 suggests that $\mathrm{TKI}_{\mathrm{C}}$ and $\mathrm{TKI}_{\mathrm{Q}}$ in each stage of a value chain will be positively correlated in a competitive environment. Less than perfect positive correlation $(\rho<+1)$ implies either production costs in excess of the economic minimum (operation on an isocost more distant from the origin) or production quantities below the technical maximum (operation on an isoquant closer to the origin). It is therefore probable 
that performance in any stage of a value chain will be positively correlated with the correlation of $\mathrm{TKI}_{\mathrm{C}}$ and $\mathrm{TKI} \mathrm{Q}_{\mathrm{Q}}$ in that stage. This can be formally hypothesized as:

Proposition 8: The greater the degree of correlation between $T K I_{C}$ and $T K I_{Q}$ in a stage of a value chain the greater will be its performance.

In many industries we also observe two vertically adjacent stages of production integrated in a single firm in some cases and simultaneously de-integrated in two vertically separated firms in other cases. Propositions 4 and 5 suggest that vertically adjacent stages in a value chain are more likely to be found separated by an inter-firm boundary as their $\mathrm{TKI}_{\mathrm{C}}$ and $\mathrm{TKI}_{\mathrm{Q}}$ diverge. Integration of adjacent stages of a value chain into a single firm when their $\mathrm{TKI}_{C}$ and $\mathrm{TKI}_{\mathrm{Q}}$ are divergent implies a lack of efficiency as Proposition 3 no longer holds for one or both of the stages. Similarly, de-integration of adjacent stages when their TKIC and $\mathrm{TKI}_{\mathrm{Q}}$ are equivalent could indicate potential loss of economies of vertical integration. Accordingly, it is reasonable to expect that, to the extent that adjacent stages are not integrated or de-integrated as hypothesized in Propositions 4 and 5, they will be performing at sub-optimal levels.

Birkinshaw, Nobel and Ridderstråle (2002) found evidence for their hypotheses that characteristics of knowledge are important predictors in the determination of inter-unit integration in R\&D organizations. However, evidence that alignment between knowledge characteristics and organizational structure was related to performance was more ambiguous (Birkinshaw et al., 2002). They caution however, that the results of their study should be seen as exploratory and not necessarily generalizable to other settings (Birkinshaw et al., 2002).

Bontis, Crossan \& Hulland (2002) found support for the proposition that the misalignment of stocks and flows in an overall organizational learning system is negatively associated with business performance. The research utilized the constructs developed in Crossan, Lane \& White (1999) in which individual and group level learning roughly correspond to tacit knowledge, organizational level learning translated into routines, prescribed practices and information corresponds to codified knowledge, and organization level learning, embedded in new products and structures, essentially corresponds to encapsulated knowledge. Misalignment is described as possibly being attributable to a flawed organizational structure.

Given the mixed results of previous studies, the relationship between the alignment of knowledge and structure to performance will be analyzed as follows. 
Proposition 9: The greater the degree of correlation of vertical de-integration to differences in $\mathrm{TKI}_{\mathrm{C}}$ and $\mathrm{TK} \mathrm{I}_{\mathrm{Q}}$ between adjacent stages of a value chain, the greater will be their performance.

\section{Conclusions and Implications}

The conceptual framework set out in this paper provides the basis for an empirical investigation into the key strategic issue of vertical firm boundary location. The proposed research aims to answer the challenge posed by Williamson (1999: 1097) to demonstrate why some activities are better organized "in a unified firm $(\mathrm{AB})$ rather than in two autonomous firms (A and $\mathrm{B})$ " and vice versa, by "applying an economic calculus to knowledge" (Simon, 1999: 34). The basic premise is that specialization leads to differences in knowledge-based factor intensities which are determinative in economic inter-firm boundary location.

A number of contributions are expected to derive from this research. First, it provides a framework for empirically testing Demsetz's (1988) assertion that differences in the cost of knowledge across a vertical inter-firm boundary are causal in boundary creation. Second, it seeks to provide evidence that variations in the cost and productivity of knowledge-based factors along a value chain originate from differences in the nature of knowledge. Third, the research will encourage the development of an instrument to measure relative differences in knowledge-based factor intensity along a value chain. Fourth, it should provide evidence that differences in the nature of knowledge employed along a value chain impacts the location of inter-firm boundaries. Fifth, the research should provide evidence that progressive specialization in knowledge along a value chain causes increased vertical de-integration over time. Finally, it should provide evidence that the 'correct' application of knowledge-based criteria in the setting of inter-firm boundaries impacts firm performance.

The expected results of the research suggested in this paper have a number of practical and theoretical implications. On the practical side, the results would suggest that firms adopt a knowledge-based view in making their 'make-or-buy' and 'sell-or-develop further' decisions, and that firms will be rewarded for making decisions on this basis. It would also suggest that firms should expect to see their value chain de-integrate over time as a natural outcome of the specialization of products and production processes.

On the theoretical side, this research will extend the knowledge-based view of the firm in the discipline of strategic management. Perhaps most significantly however, it will assist in the legitimization of "applying an economic calculus to knowledge" (Simon, 1999: 34) in KBV strategy. 


\section{References}

Argyres, N. (1996) "Evidence on the Role of Firm Capabilities in Vertical Integration Decisions", Strategic Management Journal, 17, 129-150.

Balconi, M. (2002) "Tacitness, codification of technological knowledge and the organization of industry", Research Policy, 31, 357-379.

Barney, J. B. (1991) "Firm resources and sustained competitive advantage", Journal of Management, 17, 99-120.

Birkinshaw, J., Nobel, R. and Ridderstråle, J. (2002) "Knowledge as a Contingency Variable: Do the Characteristics of Knowledge Predict Organizational Structure", Organization Science, 13, 274-289.

Boisot, M. H. (1998) Knowledge Assets: Securing Competitive Advantage in the Information Economy, Oxford University Press, Oxford.

Bontis, N., Crossan, M. M. and Hulland, J. (2002) "Managing an Organizational Learning System by Aligning Stocks and Flows", Journal of Management Studies, 39, 437-469.

Choo, C. W. (1998) The Knowing Organization: How Organizations Use Information to Construct Meaning, Create Knowledge, and Make Decisions, Oxford University Press, New York.

Choo, C. W. (2002) Information Management for the Intelligent Organization: The Art of Scanning the Environment, American Society for Information Science and Technology, Medford.

Crossan, M. M., Lane, H. W. and White, R. E. (1999) "An Organizational Learning Framework: From Intuition to Institution", Academy of Management Review, 24, 522-537.

Demsetz, H. (1988) Ownership, Control, and the Firm, Basil Blackwell Ltd., Oxford.

Demsetz, H. (1991) "The Theory of the Firm Revisited", In The Nature of the Firm: Origins, Evolution, and Development (Eds, Williamson, O. E. and Winter, S. G.) Oxford University Press, New York, pp. 159-178.

Dierickx, I. and Cool, K. (1989) "Asset Stock Accumulation and Sustainability of Competitive Advantage", Management Science, 35, 1504-1511.

Down, J. (2000) "Tacit Knowledge in Professional Practice: Researcher and Practitioner Perspectives. (Book Review)", Administrative Science Quarterly, 45,170 . 
Grant, R. M. (2002) "The Knowledge-Based View of the Firm", In The Strategic Management of Intellectual Capital and Organizational Knowledge (Eds, Choo, C. W. and Bontis, N.) Oxford University Press, Oxford, pp. 133-148.

Grant, R. M. and Baden-Fuller, C. (2004) "A Knowledge Accessing Theory of Strategic Alliances", Journal of Management Studies, 41, 61-84.

Griliches, Z. (1979) "Issues in Assessing the Contribution of Research and Development to Productivity Growth", Bell Journal of Economics, 10, 92-116.

Hedlund, G. (1994) "A Model of Knowledge Management and the N-Form Corporation", Strategic Management Journal, 15, 73-90.

Jacobides, M. G. (2003) London Business School, Centre for the Network Economy.

Jacobides, M. G. and Hitt, L. M. (2003) Centre for the Network Economy, London Business School.

Jacobides, M. G. and Winter, S. G. (2003) Reginal H. Jones Center, The Wharton School, University of Pennsylvania.

Kogut, B. and Zander, U. (1992) "Knowledge of the Firm, Combinative Capabilities, and the Replication of Technology", Organization Science, 3, 383-397.

Langlois, R. N. (2001) "Knowledge, Consumption, and Endogenous Growth", Journal of Evolutionary Economics, 11, 77-93.

Langlois, R. N. and Robertson, P. L. (1996), Vol. 2003 University of Connecticut, Department of Economics.

Lawrence, P. and Lorsch, J. (1967) Organization and Environment, Harvard University Press, Cambridge.

Macher, J. T. and Mowery, D. C. (forthcoming, 2004) "Vertical Specialization and Industry Structure in High Technology Industries", In Business Strategy over the Industry Lifecycle - Advances in Strategic Management, Vol. 21 (Ed, McGahan, A. M.).

Nelson, R. and Winter, S. G. (1982) An Evolutionary Theory of Economic Change, Belknap Press, Cambridge.

Nonaka, I. (1994) "A dynamic theory of organizational knowledge creation", Organization Science, 5, 14-37.

Pfaffmann, E. (1998) In DRUID Summer Conference on Competence, Governance, and EntrepreneurshipBornholm, Denmark, pp. 32. 
Pfaffmann, E. (2000) "Knowledge Maturity, Modularity, and the Vertical Boundaries of the Firm", In Competence, Governance, and Entrepreneurship Advances in Economic Strategy Research (Ed, Mahnke, V.) Oxford University Press, Oxford.

Polanyi, M. (1966) The Tacit Dimension, Routledge \& Kegan Paul, London.

Porter, M. E. (1980) Cometitive Strategy, Free Press, New York.

Porter, M. E. (1985) Competitive Advantage, Free Press, New York.

Prahalad, C. K. and Bettis, R. A. (1986) "The Dominant Logic: A New Linkage Between Diversity and Performance", Strategic Management Journal, 7, 485502.

Ricardo, D. (1817) On the Principles of Political Economy and Taxation.

Robinson, J. V. (1933) The Economics of Imperfect Competition, Macmillan, London.

Romer, P. M. (1990) "Endogenous Technological Change", Journal of Political Economy, 98, S71-S102.

Saviotti, P. P. (1998) "On the dynamics of appropriability, of tacit and of codified knowledge", Research Policy, 26, 843-856.

Simon, H. A. (1999) "The Many Shapes of Knowledge", Revue d'Économie Industrielle, 88, 23-39.

Varian, H. R. (2003) Intermediate Microeconomics: A Modern Approach, Norton, New York.

Williamson, O. E. (1999) "Strategy Research: Governance and Competence Perspectives", Strategic Management Journal, 20, 1087-1108.

Winter, S. G. (1987) "Knowledge and Competence as Strategic Assets", In The Competitive Challenge: Strategics for Industrial Innovation and Renewal (Ed, Teece, D. J.) Ballinger, Cambridge.

[1] A value system is the term used to describe a series of firms' value chains, where upstream suppliers are linked by markets to downstream buyers. A firm's competitive advantage depends not only on its ability to create value or reduce cost in its own value chain relative to competing firms, but also on the value-creating and cost-reducing abilities of the other firms in the value system. A value chain is a set of interrelated generic activities common to a wide range of firms. The goal of these activities is generate a profit by creating value that exceeds the cost of providing a product (good or service). These primary value-creating activities are facilitated by less linear, more pervasive, support activities. Value chain analysis involves the identification of firmspecific activities, and the process flows that link them. Understanding these activities and how 
the performance or cost of one activity affects the others can illuminate opportunities for obtaining or improving a competitive cost or differentiation advantage. [Porter, M. E. (1985) Competitive Advantage, Free Press, New York, Porter, M. E. (1980) Cometitive Strategy, Free Press, New York.]

[2] Labour (capital) factor intensity is the relative importance of labour (capital) versus capital (labour) or other factors in production, and is usually compared across firms, industries and nations. Factor intensities may be defined by ratios of factor quantities employed or by marginal rates of substitution between factors.

[3] Isoquant curves display combinations of factors of production that generate the same total quantity of output. Isocost curves display combinations of factors of production that incur the same total cost. When a firm operates on an isocost curve just tangent to an isoquant curve, it does so at the lowest possible total cost. Correspondingly, when a firm produces on the isoquant curve furthest from the origin and just tangent to its isocost curve, it maximizes output at a given cost. The slope of a firm's two-factor isocost curve is the negative of the price ratio between the two factors. The slope of a firm's two-factor isoquant curve is the negative of the marginal rate of technical substation between the two factors. A Pareto efficient production solution occurs when the price ratio between two factors equals the marginal rate of technical substitution.

[4] In two dimensions, an isocost curve shows combinations of two factors of production or inputs that generate the same total cost. An isoquant curve depicts combinations of two factors of production or inputs that generate the same total output. A firm produces a given output at the lowest possible cost by operating where an isocost curve is just tangent to the isoquant curve for that level of output. Similarly, a firm produces at the highest possible technical efficiency by operating where an isoquant curve is just tangent to the isocost curve for that level of cost. The slope of an isocost curve is the negative of the ratio of the price of the factor on the horizontal axis to the price of the factor on the vertical axis. Similarly the slope of an isoquant curve is the negative of the marginal product of the factor on the horizontal axis divided by the marginal product of the factor on the vertical axis. This slope is called the marginal rate of technical substitution of the factor on the vertical axis for the factor on the horizontal axis. At the efficient solution, the price ratio and the marginal rate of technical substitution between the two factors are equal.

[5] To simplify the construction of Figure 1, knowledge-based production factors have been limited to two; the classifications of codified knowledge and encapsulated knowledge were collapsed into a single factor, explicit knowledge. In operationalization of the research, codified knowledge and encapsulated knowledge are expected to be treated as separate and distinct input factors owing to important differences as dimensionalized in Table II. Choices between the employment of codified or encapsulated knowledge are considered to be strategically significant because of these differences.

[6] See previous footnote.

[7] The law of diminishing marginal product states that increases in an input, holding all other inputs constant, will result in lower marginal product. In other words as the quantity of one factor of production is increased, while all other factors are held constant, at some point the rate of increase in product will diminish. 
$\left.{ }_{8}\right]$ If there is more than one way to produce an output, firms can exploit comparative advantages [Varian, H. R. (2003) Intermediate Microeconomics: A Modern Approach, Norton, New York.]. The law of comparative advantage states that producers will specialize in the production of goods and services for which they have the lowest marginal opportunity cost. Comparative advantage was shown by David Ricardo to be more generally applicable than absolute advantage [Ricardo, D. (1817) On the Principles of Political Economy and Taxation.]. Even if one of two parties to a potential market exchange has an absolute advantage in the production of both two products to be traded, that party can still increase its utility beyond that available at its production possibility frontier by specializing in the production of that good or service in which it has a comparative advantage, and trading for that in which it has a comparative disadvantage. 